Revista de la red interuniversitaria de estudios sobre las literaturas rioplatenses contemporáneas en Francia

$10 \mid 2014$

El XIX en el XX

\title{
Echeverría entre dos siglos : las fundaciones de la crítica
}

Cristina Iglesia

(2) OpenEdition

Journals

Edición electrónica

URL: http://journals.openedition.org/lirico/1709

DOI: 10.4000/lirico.1709

ISSN: 2262-8339

Editor

Réseau interuniversitaire d'étude des littératures contemporaines du Río de la Plata

\section{Referencia electrónica}

Cristina Iglesia, « Echeverría entre dos siglos : las fundaciones de la crítica », Cuadernos LIRICO [En

línea], 10 | 2014, Puesto en línea el 15 marzo 2014, consultado el 30 abril 2019. URL : http:// journals.openedition.org/lirico/1709; DOI : 10.4000/lirico.1709

Este documento fue generado automáticamente el 30 abril 2019.

\section{(c) $(1) \odot$}

Cuadernos LIRICO está distribuido bajo una Licencia Creative Commons Atribución-NoComercialSinDerivar 4.0 Internacional. 


\title{
Echeverría entre dos siglos : las fundaciones de la crítica
}

\author{
Cristina Iglesia
}

\section{NOTA DEL AUTOR}

Una versión más amplia de este artículo se publicará en el volumen I, La patria Literaria, de la Historia Crítica de la literatura argentina coordinado por Cristina Iglesia y Loreley El Jaber y dirigida por Noé Jitrik que aparecerá en 2014.

1 A lo largo de casi dos siglos la obra y la figura de Esteban Echeverría han sido objeto de complejas y muy variadas construcciones críticas. Hay dos tiempos claves en este proceso : el de la recepción de sus contemporáneos, liderada por Juan María Gutiérrez (1830-1850), y la que se produce luego y a partir de que el mismo Gutiérrez publicara las Obras Completas (1870-1874 hasta el presente). Esta multifacética saga crítica se ha ido conformando, a su vez, al influjo de tres dimensiones que casi siempre se entrecruzan : la de la constitución de una literatura nacional, la de la valoración estética de la obra echeverriana y la de sus usos según las urgencias y necesidades de las coyunturas políticas de nuestra historia. Este artículo intenta abordar esos tiempos y esas dimensiones, ensayando, como no podía ser de otro modo, su propio relato.

\section{El único poeta en la ciudad}

2 Los primeros poemas y el primer poemario de Echeverría se publican sin nombre de autor y con mucha distancia entre uno y otro. ${ }^{1}$ Todas estas publicaciones tendrán, cada una en su momento, una importante repercusión periodística. Pedro de Angelis en El Lucero, Miguel Valencia en El telégrafo de Comercio, Thomas George Love en The British Packet ${ }^{2}$ los comentan con tono benevolente y escaso entusiasmo aunque ninguno de ellos utiliza, ni por asomo, un tono ofensivo. Sin embargo, las notas provocan en Echeverría la necesidad de enfrentar a los "periodistas argentinos" quienes debido a su "vil profesión", que los 
convierte a sus ojos en "bastardos gaceteros", no estarían en condiciones de apreciar la calidad de su poesía. La Sátira a los periodistas argentinos que se inicia con una lapidaria cita de Byron "They write for food and feed because they write", no deja, como quien dice, nación sin cabeza ya que Italia, Inglaterra y España, representadas en sus súbditos locales - De Angelis, Love y Valencia- serán incriminadas por ser potencias imperiales y sus súbditos locales serán ferozmente atacados como si ellos hubieran ofendido a la patria misma. ${ }^{3}$ La queja se extiende también a la pasividad del público porteño que tolera estos agravios : "¿Y aquesto se tolera entre nosotros? ¿Do el noble orgullo está ? ¿Do la energía de los claros porteños ? ¿Por qué dejan insultar a la Patria en sus desdichas ?”.

La Sátira, de una trabajosa y fallida urdimbre, no fue incluida por Gutiérrez en las Obras Completas y no hay registro de que sus contemporáneos la hubieran conocido en manuscrito. Sin embargo muestra, en el reverso de la trama, la temprana intolerante postura del poeta frente a cualquier atisbo de crítica de su obra y explica también su temprano repudio a los periodistas y al periodismo en general. Una carta de Echeverría a José María Fonseca enviándole el poema que le dedica, publicada por Gutiérrez, muestra también cuán temprana es la queja por sus pesares y las dolencias que habrían "cortado las alas de mi imaginación y amortiguado el fuego divino de mi espíritu” y cuán temprana es la comprensión de lo difícil que le resulta convertirse en escritor. ${ }^{4}$

\section{El éxito}

4 Pero entre la publicación de Elvira y la de Los Consuelos se produce en la vida de Echeverría un hecho que sería clave para su biografía y, por ende también, para la historia de la literatura nacional. El encuentro con Gutiérrez, unos años mayor, lector voraz, curioso y con numerosas relaciones entre la elite porteña y montevideana, articula una amistad que tendría consecuencias no sólo en la producción inmediata de Echeverría (los cinco años más intensos de su escritura, del 33 al 38) sino también en el modo en que, después de la muerte del poeta, su obra y su vida serían narradas y organizadas para la posteridad.

En carta a Pío Tedín, un antiguo condiscípulo salteño que había regresado a su provincia, Gutiérrez introduce a su nuevo amigo :

Ahora paseo con Echeverría. Este joven llena mis gustos, es instruido, entusiasta, le gustan los paseos extramuros y nos entendemos perfectamente" $\mathrm{Y}$ más adelante"Ahora estamos editando sus poesías (...) es un libro perfecto y bello por la forma y la materia. Está impreso como si fuera en Europa y forrado en papeles de colores los más exquisitos (..) Haga Ud.que los demás amigos, sus conocidos y señoritas encarguen un ejemplar porque merece leerse y verse. ${ }^{5}$

6 La carta, de octubre de 1833, describe el momento crucial del encuentro con el nuevo amigo pero también muestra a Gutiérrez colaborando en la edición del que será el primer libro exitoso del poeta, imaginando un público que incluye señoritas, dando un fuerte impulso a su circulación. La carta muestra así el origen de lo que se convertirá en la línea de trabajo más importante de Gutiérrez : reseñar primero, editar y hacer circular después la obra publicada y la obra inédita de Echeverría, mantenerlo vivo en vida y después de su muerte. Los Consuelos fue el primer libro de poemas impreso en el país y tuvo gran repercusión en Buenos Aires y Montevideo : las reseñas de Juan Thompson, de Valentín Alsina y del propio Gutiérrez, así como los comentarios en cartas de Bartolomé Mitre y de Florencio Varela, entre otros, así lo confirman. ${ }^{6}$ En fin, como afirma Abel Chanetón, "la 
consolidación del prestigio intelectual y la auténtica popularidad de Echeverría nacen de allí."

\section{La Cautiva : operación poética e intervención cultural}

7 A partir de la publicación de las Rimas Echeverría sería, desde entonces y por muchas décadas, el autor de La Cautiva.

8 Trabajado en el espacio de la pampa, el poema narra una historia de rapto, cautiverio y muerte. La tribu errante, un colectivo sanguinario que cruza el desierto cual torbellino, se detiene para gozar de la orgía después de haber atacado un puesto de frontera. El poema comienza justo en el momento en que los indios irrumpen y allí aparece, ensartada en la pausa del movimiento arrasador, la historia de amor trunca de María y Brian que le otorgará un dramatismo inédito. Raptada y hecha prisionera, como su amado, de estos salvajes, la cautiva blanca lucha para salvar su vida y la de su hombre. Armada de un coraje y una entereza inusitadas, esta heroína enfrenta a sus captores al tiempo que enfrenta el deshonor al que la somete su involuntario destierro. A pesar de su bravura, María ve morir a su amado entre sus brazos y sabe poco después que su pequeño hijo también ha muerto. Los versos esconden el sufrimiento de la cautiva en episodios sucesivos que subrayan su valentía y la cobardía de los indios y, previsiblemente, María muere también antes de que el poema termine, atormentada por el sufrimiento de sus amadas pérdidas.

9 La historia de la cautiva blanca está en el origen de la conquista del Río de la Plata, más precisamente en un episodio ubicado en La Argentina (1612), el primer libro de la historia de la conquista del Río de la Plata escrita por un mestizo, Ruy Díaz de Guzmán. En este episodio, Lucía Miranda se convierte en un mito blanco y cristiano. A través de ella los conquistadores definen al espacio americano como propio y al indio como violador de la frontera. ${ }^{8} \mathrm{Al}$ colocar esta historia de un cuerpo femenino violado por el cuerpo bárbaro en el centro de su poema, al colocar esta historia y no otra como "fondo" de su obra de imaginación, Echeverría funda para la literatura argentina la dicotomía civilizaciónbarbarie que Sarmiento elaborará a su manera en el Facundo.

La barbarie se escande en múltiples rasgos hasta llegar a la vampirización o la demonización : los indios tienen gritos en lugar de voz, son feroces (y su ferocidad puede volverse contra ellos mismos: pueden despedazarse, son "feos", son "beodos", son bebedores de sangre de yegua ; son cuerpos "rellenos de sangre", es decir, son "vampiros" o habitantes del abismo. Si algunos tienen nombres (Quillán, Callupán, Chanil) es sólo por americanizar la lengua del poema. Los nombres no definen personajes, se leen y se escuchan como sonidos nuevos que permiten escuchar el ruido de la barbarie.

11 El poema despliega también un enfrentamiento sangriento y confuso entre soldados y salvajes pero el combate no emplaza una frontera, ni siquiera la defiende o la desplaza. Esta batalla no es gloriosa para ninguno de los bandos y no se advierte en ella ninguna señal del patriotismo heroico que de vez en cuando el poema adjudica a Brian y a sus soldados. Hacia el final, el desierto parece volver a cubrirlo todo, como si nada hubiera sucedido. El único límite reconocible en el poema está en su borde: es ese espacio heterotópico adornado por la fantasmagoría del gótico : la tumba de María, una cruz, un ombú y las luces de aparecidos hacen que esa tierra de nadie sea para los que la transitan, 
cual cautivos que huyen de los indios o indios mismos, un territorio sagrado o aterrorizante, un límite.

Con La Cautiva y su novedosa urdimbre de un paisaje y una historia americana, Echeverría había escrito, finalmente, el poema que sus contemporáneos necesitaban. Había escrito el poema del presente, pero también el poema del futuro. Poco importaría, a partir de entonces, que los versos no fueran felices ni que el conjunto no tuviera contundencia estética : su eficacia consistió en actualizar un mito que la historia colonial había fundado para disimular su violencia y convertirlo en un mito patriótico. Pero sobre todo, en presentarse ante los ansiosos jóvenes necesitados de poesía nacional con una obra que pudieran sentir como propia y proyectar como herencia hacia el futuro.

\section{El poema y las operaciones de la crítica}

Pocos días después de la aparición de las Rimas, Gutiérrez publica en dos números sucesivos del Diario de la tarde un extenso ensayo sobre la producción de Echeverría hasta el momento. El texto importa por varias razones : por un lado, es el primer ensayo crítico dedicado a la obra de un escritor contemporáneo ; por otro, establece con firmeza el lugar que ocupa dicha obra en la incipiente literatura argentina; y, además, en un gesto novedoso, tiene en cuenta la importancia del propio texto crítico en la valoración de la obra. Pero hay más motivos de interés : el ensayo se propone en primera instancia como suplemento o reemplazo de un supuesto manifiesto estético que Echeverría habría desistido de poner al frente de su libro por razones que el crítico también imagina libremente :

Sabemos a no dudarlo que el autor tenía premeditado el poner al frente de su nueva publicación, una teoría extensa y nueva sobre el arte o sobre su metafísica estética. Este trabajo interesante para los estudiosos, serviría a la vez al poeta, ya de escudo contra los tiros ciegos de la crítica descaminada, ya para colocar al lector en el punto de vista adecuado a la talla de sus personajes, a las sombras, luces y colorido de sus cuadros. Serviría, igualmente, de antorcha fiel para seguirle los pasos en el camino de su pensamiento, decidiéndonos a proseguir por su vía o darle las espaldas tomando otro sendero. Ha desistido por ahora, de su propósito, considerando sin duda que aún no ha cerrado el círculo de sus trabajos artísticos, ni hecho vibrar todas las cuerdas de su harpa, condición necesaria para poseer todos los materiales con que debe alzar el edificio de su teoría. ${ }^{9}$

Gutiérrez inaugura así un peculiar modo de acompañar y defender la obra de su amigo que mantendría a lo largo de todo su proyecto: afirmar que conoce las intenciones del autor aunque este no llegue a plasmarlas en escrituras, conjeturar los alcances de esas líneas si hubieran realmente existido y escribir en su nombre los faltantes. El efecto de esta operación será asombroso porque a fuerza de repetirla en diferentes momentos de su trabajo crítico hasta el lector más atento se convencerá de que Echeverría pensó, proyectó y escribió lo que Gutiérrez describe con tanto detalle.

En este manifiesto crítico premonitorio, "La Cautiva" es el poema articulado en la naturaleza, la naturaleza misma crea las formas estéticas adecuadas para su expresión :

Cuando el lugar de las escenas de La cautiva es nuevo y recién descubierto para el arte, cuando en él resuena el alarido del salvaje de la pampa ; serpean las llamas del incendio, la sequía esteriliza y yerma, el yajá se levanta fatídico sobre todo este mundo raro que 
anima el poeta, imposible era someterse a una forma que no naciese espontáneamente del seno de estas mismas cosas. Así nace, y la forma queda santificada, sin necesidad de mayor examen y apología. ${ }^{10}$

18 La valoración del paisaje como elemento que da forma al poema y no como un espacio al que el poema alude, es una audaz e inteligente lectura del incipiente crítico que inaugura así una línea interpretativa de La Cautiva que tenderá a privilegiar la construcción del desierto, el pingüe patrimonio que el poeta señala como bien nacional, por sobre la historia misma que otorga ritmo y dramaticidad a la obra. Pero, a pesar de su entusiasmo, el primer gran lector advierte una falta, un algo de incumplido en los versos que analiza. Advierte, vigilante, que el poeta "está al umbral de la poesía social y religiosa" que se anhela y promete a sus lectores y se promete a sí mismo que el vate, el elegido, cruzará un día ese umbral para otorgarles el poema deseado. Allí está la palabra del crítico para refrendar la importancia de lo que ha logrado y augurar un próximo final de espera : "Qué mayor elogio podríamos hacer de las mencionadas poesías que recordar que ellas nos han sugerido estas serias consideraciones (...) esperamos sí que llegará el día en el que el autor de las Rimas nos de margen a decir todo lo contrario". ${ }^{11}$

Desde entonces, la obra de Echeverría estará, literalmente, en manos de Gutiérrez : su primer libro ha iniciado su circulación rodeado de la escritura del crítico, de sus alabanzas y de sus retaceos, de sus entusiasmos y de sus presiones. La Cautiva será presentada en la sociedad de letrados, cuando el mismo Gutiérrez la lea en voz alta en las primeras sesiones del Salón. En esa lectura en voz alta resuena el eco de la antigua oratoria patriótica : ahora lo que se lee, lo que debe escucharse, es una proclama de nuevo tipo, una proclama de política literaria.

20 Casi un siglo después, el poema será nuevamente puesto a prueba. En su monumental Historia de la Literatura Argentina, Ricardo Rojas lo manipulará con el entusiasmo de un fundador :

el argumento de La Cautiva se reduce a un episodio de nuestra vida de frontera, el rapto de una cristiana por los indios y todos los episodios de valor o pillaje que, entre escenas de sangre y de fuego, constituían el drama de nuestras estancias, en aquella zona liminar de la civilización argentina.

21 Esta descripción del argumento sumada al uso de versos endecasílabos, posibilita que Rojas incluya el poema de Echeverría en el volumen correspondiente a "Los gauchescos". Se trata de una operación crítica excesiva -muchos la considerarán "irreverente" según el mismo Rojas- porque recorta el poema del resto de la producción de Echeverría para leerlo no en el contexto de la producción del poeta sino en la serie de la poesía gauchesca. Con esta operación coloca al poema en la zona de la historia de la literatura argentina que Rojas considera verdaderamente original y propia. Para el crítico, la genuina literatura nacional se inicia con la gauchesca que, a su vez, constituiría el principal aporte de la literatura argentina a la constitución de una nueva literatura americana. Con el poeta instalado, a partir de La Cautiva en la serie señera, Rojas enfatizará su lugar en la Historia de la literatura argentina : "La gloria de Echeverría consiste no sólo en haber creado esta nueva corriente más progresiva, fecunda y universal que la gauchesca sino en ser el primer poeta que compusiera un poema con argumento pampeano en verso culto" 12 . Echeverría no sólo se elevaría por sobre la primera gauchesca sino que habría alentado la superación de su fragmentarismo permitiéndole ingresar a los grandes dominios de la épica. En otras palabras, La Cautiva habría alentado el Santos Vega de Ascasubi, publicado en París en 1851 y con el que la gauchesca llegaría a cumbres épicas. Ambos poemas 
constituirían, así, las dos piedras fundamentales de la nueva poesía nacional coronada por el Martín Fierro de Hernández. Esta osada conjunción se apuntala en el común uso del octosílabo, en la incorporación de los indios y en el hecho de que ambos poemas fueran compuestos en estancias cercanas a Buenos Aires. Surgidos en "Los talas" y en "La Flor" los versos habrían sido impregnados por el paisaje y la atmósfera americana que rodeaba a los escritores. En el vértigo de su construcción, Rojas llega a imaginar una incidencia directa de un texto en otro y una probable amistad entre ambos vates. ${ }^{13} \mathrm{El}$ crítico dispone las piezas del monumento entramando biografías, ritmos y usos de la lengua. Pero a pesar de su entusiasta voluntarismo, no deja de anotar su preferencia por Ascasubi frente a "los desmayos en la versificación, los ripios con que rellena el verso, las voces imprecisas en que deslie el pensamiento, las palabras triviales con que afea las rimas" y sobre todo "la ausencia de emoción poética" en el poema de Echeverría. ${ }^{14}$ Sin embargo la valoración estética es superada por la necesidad crítica: en el momento en que Rojas organiza su Historia, La Cautiva es el poema que le permite sentar las bases de su precario monumento.

En las últimas décadas del siglo veinte, Adolfo Prieto realiza otra operación crítica importante al leer en La Cautiva algo que sus epígrafes se empeñarían en ocultar : el hecho de que el viaje y la mirada del viajero son elementos constitutivos de la construcción del poema. Así, desde la primera estrofa :

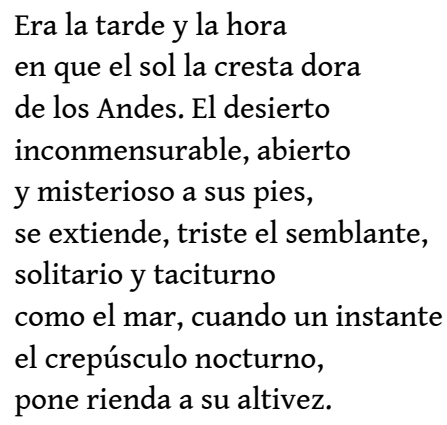

La voz poética habla desde la cordillera y utiliza la misma imagen comparativa que el texto de Humboldt. El narrador del poema, siempre en la perspectiva de Prieto, se coloca ahora como un observador en el arranque mismo de la llanura y, al mismo tiempo, en la perspectiva de un observador que se mueve, camina y cabalga en una dirección desde la que registra lo que ve :

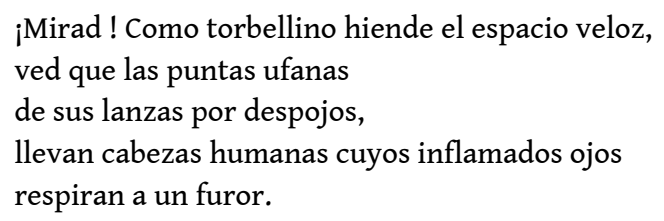

24 El testigo ocular, el viajero, invita a compartir la descripción de la orgía que los indios celebran esa noche. Y cuando María y Brian irrumpen en la historia, el poema acompañará su huida con motivos característicos del itinerario de un viajero por ese mismo territorio : el pajonal, el pantano, el nido del chajá, los incendios favorecidos por la sequía, el encuentro con el tigre, esto es, los amantes pasarán por tribulaciones propias del género a las que estos personajes sirven, según Prieto, como "agentes vicarios".

La perspectiva de Prieto permite ver la incidencia de la literatura de viajes en el mismo espacio del desierto, el espacio más romántico. ${ }^{15}$ Hace visible una presencia que habría sido borrada por deseo expreso de Echeverría al colocar epígrafes de Hugo, Dante, Calderón, Manzoni, Moreto, Lamartin, Petrarca y ninguno que aludiera a los viajeros 
ingleses, como lo hicieron explícitamente Sarmiento o Alberdi por ejemplo. Leída en esa serie, $L a$ Cautiva permite ver también la trama de apropiaciones y elisiones en que se funda la incipiente literatura nacional.

El éxito del poema es también el de su perduración como matriz de un sistema de alusiones que sigue fascinando a críticos y escritores. ${ }^{16}$

\section{0 : el renacimiento del escritor}

"La sombra de Echeverría se levanta! Es la sombra de un pensador, es la sombra de un poeta! Un noble amigo la guía y la introduce solemnemente en la región de los vivos"

Pedro Goyena

La aparición de las Obras Completas de Echeverría, el maestro de la juventud por excelencia, editadas y ordenadas por Juan María Gutiérrez es saludada así por Pedro Goyena, un joven intelectual de la década del 70. En la fantasmagórica imagen, la figura de Gutiérrez es la que posibilita que la de Echeverría surja de la muerte, surja del olvido. Esta enorme tarea individual y esta fuerte apuesta editorial tienen, por cierto, una justificación sencilla : el autor al que de este modo se honra sería el vínculo natural que "liga" las generaciones que ingresan a la vida ciudadana en los setenta con la de los padres fundadores.

La idea de un autor y una obra que funcionarían como "ligamento" entre el momento de fundación de la patria y el actual, en el que conflictos internos de diverso tipo parecerían impedir su organización definitiva, resulta eficaz sobre todo teniendo en cuenta un pasado inmediato en el que el rosismo y el post Caseros parecían haber fracturado la coherencia política y cultural del imaginario liberal de esa construcción.

29 La edición en cinco tomos emprendida por la Imprenta de Carlos Casavalle incluye las obras que Echeverría publicó en vida y un número notable de páginas inéditas que su amigo, constituido en albacea post mortem, habría encontrado bajo la forma informe de un amontonamiento de papeles, un cúmulo de hojas sueltas de calidad material deficiente, atiborradas de una letra que se expande desprolija, garabateada con plumas muy usadas y tintas desleídas que dificultan su lectura al tiempo que dan cuenta de la precariedad de las condiciones materiales en que esa escritura se produce.

Los escritos inéditos son de muy variada índole: notas a la manera de epístolas que podrían contener material autobiográfico, reflexiones sobre estética y literatura, fragmentos de piezas dramáticas, trozos de relatos de viaje figurados, listas de frases y modismos. Se trata de transcripciones realizadas por Gutiérrez que suelen ir acompañadas por comentarios sobre la importancia específica de tal o cual fragmento o sobre lo difícil que le resulta entender la endiablada caligrafía de su amigo. Las quejas del investigador, enfrentado a la triple tarea de entender, transcribir y editar nos descubren también que ha tenido que dejar de lado muchos "fragmentos" por ininteligibles o simplemente por considerarlos prescindibles. Es decir nos muestran que las Obras Completas no lo son tanto y que su contribución - cortando, eligiendo, desechando- no ha sido para nada secundaria. Un momento notable es aquel en el que podemos literalmente ver a Gutiérrez desentrañando los renglones de dos piezas fundamentales de Echeverría 
que hasta el momento habían permanecido inéditas: se trata de las famosísimas "lecturas" que el poeta habría llevado a cabo en el ámbito del Salón Literario :

Éntre los informes borradores de estas lecciones hemos tenido la fortuna de hallar la que damos hoy á luz, seguros de que será leída con avidez, con admiración y con agradecimiento...", escribe Gutiérrez refiriéndose a la que se conoce como la primera y en cuanto a la segunda : "Esta lectura encierra el pensamiento económico de Echeverría en la fecha dé la instalación del "Salón Literario," presentado intencionalmente en aquel lugar, despojado de fórmulas técnicas y de todo aparato científico. Hasta aquí llegan los fragmentos de esta lectura, los únicos que hemos podido descifrar entre los M. SS, confusos y desordenados, que teniamos á la vísta.

Y el momento es notable porque si nos atenemos a Félix Weinberg, que ha trabajado puntualmente sobre esta cuestión, no hay en realidad ninguna prueba de que esos textos hubieran sido leídos y ni siquiera que las reuniones en que ambas lecturas se hubieran dado, hubieran en realidad, existido (El potencial se apodera, también, inevitablemente, de este ensayo, pero para quien lo haya seguido hasta este punto esto no debería ya resultar sorprendente) ${ }^{17}$ Sin ánimo de agregar ninguna conjetura sobre el momento en que habrían sido escritos o leídos estos ensayos, lo cierto es que es Gutiérrez el que, al tiempo que nos cuenta emocionado su descubrimiento, los da a conocer por primera vez en letra impresa, acompañándolos con notas que subrayan la importancia de su contenido patriótico y construyen una escena de lectura ante un grupo de jóvenes expectantes, fechada en setiembre de 1837 . No es imposible entonces que generaciones de críticos de posturas diversas, ansiosos también por asirnos a esa escena iniciática que marcaba nuestro modo de ingresar a la cultura de los tiempos modernos de la mano del poeta y pensador, hayamos leído lo que Gutiérrez quiso que leyéramos y hayamos pasado por alto lo que Gutiérrez quiso que olvidáramos. No sería, como vimos, la primera vez en que actuaríamos de este modo, pero tampoco, como veremos, sería la última.

\section{La joya del archivo}

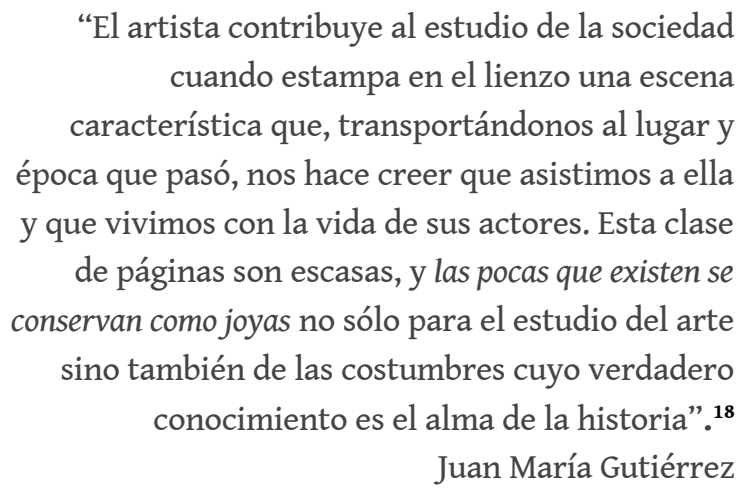

Estamos, nos dice en esta nota, frente a un descubrimiento de gran importancia, al que puede nombrar como una rara joya de esas que son escasas, difíciles de encontrar. Con esta Advertencia - el nombre, no casualmente, es el mismo que puso Echeverría a su prefacio a las Rimas- que literalmente rodea al texto que presenta al público por primera vez, Gutiérrez direcciona la lectura de su hallazgo en un doble sentido: por un lado, afirma sin vacilación que se trata de un bosquejo, de un fragmento, de algo inacabado pero que en virtud de sus méritos -señalados en el párrafo citado- merece ser conocido en tanto tal ; por el otro, imagina el momento en que su autor lo escribe (muy poco antes de partir al exilio) y la presión de la urgencia política en la escritura (la prisa y la ira 
explicarían el temblor de la letra). Y no duda en reforzar los tintes del peligro con esta asombrosa afirmación que no puede sino resonar de un modo atroz para los que conocemos la historia de nuestro país en los años setenta del siglo XX :"Si esta página hubiera caído en manos de Rosas, su autor habría desaparecido instantáneamente". Con la Advertencia, obra maestra de la crítica como invención, Gutiérrez nos regala ahora una escena de escritura extraordinaria para el que sería considerado, a partir de entonces, el primer relato, el primer cuento de la literatura nacional.

La historia de la literatura argentina tiene sus misterios y la aparición póstuma del relato más valorado de Echeverría -no bajo la forma de un original autógrafo sino de una transcripción trabajosa del amigo Gutiérrez- es, para nosotros, uno de los más inquietantes. ¿Por qué esta "joya" nunca fue nombrada ni en la correspondencia entre Gutiérrez y Echeverría ni en la de alguno de ellos con sus corresponsales frecuentes? ¿Por qué tampoco es mencionada en las tres versiones de la biografía de Echeverría que Gutiérrez escribió luego de su muerte, incluidas en el mismo volumen $\mathrm{V}$ en el que publica "El Matadero" ? ¿Por qué el exégeta valoró tanto este bosquejo inacabado si resultaba una muestra visible de ese "realismo intencional" que consideraba fatídico para la belleza de las obras literarias?

¿Hasta qué punto intervino Gutiérrez en la redacción de "El Matadero", un texto que no hubiéramos conocido jamás sin su intermediación y que, por lo tanto, otorgaba una libertad tentadora a su reconocida "manía" de mejorar o enmendar textos ajenos? El vacío de manuscrito dejará por ahora sin respuesta muchas de estas preguntas pero una cosa es ya segura : fue Gutiérrez y no otro quien nos ofreció un conjunto escriturario (el texto y su paratexto) que propiciaría múltiples lecturas críticas y poderosas reescrituras ficcionales. Es Gutiérrez, al decidir mostrar la joya del archivo en el engarce que confecciona a su medida, el que otorga un origen a la literatura argentina al mismo tiempo que lo envuelve en su propio misterio. ${ }^{19}$

\section{Lo que sucedió con El matadero después de su aparición en público}

Después de su publicación en la Revista del Rio de la Plata en 1871 y luego en las Obras Completas en 1874, El Matadero no fue citado como sí sucede con La Cautiva, cuyos versos, a partir de las Obras Completas, comienzan a ser utilizados como epígrafes o citas por otros escritores del período (el uso más notable es el que hará Lucio V. Mansilla en Una excursión a los indios ranqueles que comienza a publicarse justamente en ese momento). En la década del 80 y en plena polémica sobre el naturalismo, Luis Tamini lee el texto no como testimonio sino como ejemplo de literatura realista y Martín García Merou insistirá, en su estudio sobre Echeverría, en denominarlo "cuadro de costumbres nacionales" y, al mismo tiempo, "cuadro realista". ${ }^{20}$ Ricardo Rojas en su Historia dirá que se trata del "primer cuento verdaderamente argentino" e insistirá en su carácter realista. ${ }^{21}$

En el siglo XX críticos literarios, ensayistas, historiadores, filósofos y políticos vuelven insistentemente sobre la figura y la obra de Echeverría. En la década del 50, en particular, se produce una gran "vuelta" a Echeverría en el marco de la disputa entre intelectuales opositores al peronismo y los pertenecientes al "revisionismo histórico". En palabras de Soledad Quereillac : 
La vuelta a Echeverría se produce más en una dirección política que literaria, aunque no se obvie del todo su literatura dado que está en juego, nuevamente, la fijación o la devastación de los orígenes en pos de legitimar ideas actuales. En ese contexto, el poeta se convierte en el "apóstol" de los intelectuales antiperonistas. ${ }^{22}$

En cuanto a "El matadero" será recién en la década del 60 cuando aparezcan los estudios o las líneas de interpretación que produzcan un cambio importante en el modo en que había sido leído hasta entonces.

Sin duda la intervención crítica más significativa es la de Noé Jitrik que en "Forma y significación en El matadero" (1968) aborda desde una perspectiva propia, que incorpora sus lecturas de Barthes y Greimas, un análisis minucioso que autonomiza el texto y le otorga un estatuto definitivamente literario, proponiendo una suerte de decurso hacia la forma cuento sostenida en el narrador como función ordenadora y como instancia de transformación de lo real en ficción. ${ }^{23}$

9 En 1971, por su parte, David Viñas construye la figura del "escritor liberal romántico" entramada en una contradicción mayor: la que estos escritores instalan entre una creencia en la eficacia de las letras y su apostolado, entre su confianza en el libro como objeto civilizatorio y la resistencia sorda o activa de los sectores que encarnan el pueblo al que deberían convertir. El modo en que esta contradicción se produce es formulada por Viñas en términos ideológicos, declinados en una serie abiertamente sexual :"Pero cuando ese libro no 'entra', (el escritor liberal romántico) agrede o se repliega ; como no puede o no está dispuesto a 'abrirse', con cada ruido imaginará una 'violación"'. ${ }^{24} Y$ es esta violación la que Viñas convertirá en metáfora mayor de la emergencia de la literatura argentina: "El matadero y Amalia no son, en lo fundamental, sino comentarios de una violencia ejercida desde afuera hacia adentro, de la 'carne' sobre el 'espíritu'. De la 'masa' contra las matizadas pero explícitas proyecciones heroicas del Poeta". ${ }^{25}$ Sin abocarse a un análisis textual, Viñas instala, con una sola frase, el modo en que El Matadero inauguraría la literatura nacional y, al mismo tiempo, el modo en que sería leído a partir de entonces.

Las propuestas de Ricardo Piglia y de Martín Kohan, para citar sólo dos de las más influyentes, se despliegan a partir de esta frase pero se hacen cargo del problema crítico que significa la mediación, la distancia entre el momento de su escritura y el momento de su publicación. A partir de esta constatación, Piglia avanza en la formulación de dos órdenes posibles de escritura en el siglo XIX, la ficcional, que es la que se esconde, y la autobiográfica, que es la que se exhibe. Kohan, por su parte, subraya una cuestión central : al no publicarse en el momento de su escritura, El matadero debió renunciar a la eficacia política de la palabra inmediata pero, aún así, mediada por la distancia entre ambas fechas la violencia persiste en el lenguaje. ${ }^{26}$

Desde nuestra perspectiva el trabajo del lenguaje con la violencia entre y sobre los cuerpos es central en el Avellaneda y en El Matadero. En el primero el carácter sanguinario y brutal de la matanza y los degüellos aparece "justificado" por la lógica de la guerra (dos facciones políticas se enfrentan en el campo de batalla) pero en El matadero, la violencia y la vejación parecen gratuitas y surgen para impedir que un cuerpo extraño (el del unitario) ingrese al espacio de los federales. No hay nombres de personas, ni de lugares, ni de batallas: sus protagonistas son personajes literarios. Y precisamente por eso, la irrupción del que se convertirá en protagonista de la historia, no deja de suscitar interrogantes. ¿Quién es ese joven al que los del matadero llaman "el unitario”? ¿Por qué avanza sin temores -como si no hubiera dictadura- por zonas de los arrabales que pueden resultar peligrosas? ¿Por qué exhibe tantos signos exteriores de su rebeldía o su no 
adhesión al régimen ? ¿Su muerte convertirá su cuerpo en uno sacrificial en términos de Agamben? ¿Su heroísmo solitario dejará marcas en la memoria colectiva (como lo hará el cuerpo de Marco Avellaneda) o su muerte ignota será sólo el resultado de un juego peligroso de amenazas verbales y forzamientos físicos como los que los del matadero infligen al ganado? ¿Acaso no queda su cuerpo tendido y solo en la casilla de los carniceros, como un resto animal? ¿Acaso su sacrificio no se escurre entre los charcos de sangre del matadero en el final del cuento ? Los carniceros abandonan la escena como si no fueran culpables de esa muerte, la ficción abandona a la víctima, la deja librada a su propia suerte.

42 Y sin embargo, hay algo que lamentar : el largo párrafo final otorga sentidos referenciales a una violencia cuyo sentido sólo estaba en la ficción, advierte que debe ser leído como denuncia, no quiere que los lectores (los únicos posibles, los de 1870) se confundan por la lejanía de los sucesos. Es posible entonces proponer una pregunta más: ¿a quién pertenece este segundo final de El Matadero?

Entre tantos interrogantes, algunas cuestiones son claras : luego de la magistral operación de Gutiérrez al ponerlo en circulación en 1870 junto con su paratexto, El Matadero pasa por períodos de relativa opacidad. Es necesario esperar a las fuertes intervenciones de Jitrik y de Viñas para que este texto enigmático y esquivo se convierta en texto fundacional de la ficción argentina, comience a ser tratado como el génesis. ${ }^{27}$

Si es cierto que todo relato despliega para el lector un mundo mucho más complejo, mucho más rico que el que vive en los límites de sus páginas, en El matadero esta afirmación se cumple con creces : en sus faltantes está su completud, en sus paradojas, su riqueza.

\section{Esteban Echeverría en el siglo XXI}

Una primera conclusión : sin la intervención de Juan María Gutiérrez la obra -y la vida- de Echeverría no hubiera llegado a la historia de la literatura argentina ya convertidos -vida y obra- en las del primer escritor y pensador de la nación. Urgido por la necesidad de probar la existencia de una literatura nacional, Gutiérrez lidió tempranamente con la escasez de producción literaria de sus contemporáneos y con la insatisfacción que lo poco que había le suscitaba, incluidos, como hemos visto, los primeros poemarios de Echeverría. Cuando decide editar sus Obras Completas decide, al mismo tiempo, pasar por alto sus propias dudas y clausurar toda otra posibilidad de interpretación de un archivo que abre y cierra en un mismo movimiento. El crítico se convierte así en el único capaz de otorgarle un sentido homogéneo a esa producción, en armonía plena con la vida del autor y con el país en que esa vida tuvo lugar. Y, como para no dejar huecos, da un paso más :

como si Gutiérrez hubiese percibido -acaso inconscientemente- que los materiales que recopilan los cinco tomos de las Obras completas no eran suficientes para asegurarle a Echeverría un lugar en la posteridad literaria, intenta reforzar su estatuto mediante un audaz ejercicio conjetural o contrafáctico. Ese ejercicio consiste en declarar la innegable calidad que habría tenido aquello que Echeverría pudo haber escrito, pero no escribió, o debió de haber escrito, aunque no quedaron testimonios de que lo haya hecho. ${ }^{28}$

Superponiendo escrituras reales con escrituras posibles, Gutiérrez consuma una operación crítica cuya eficacia queda demostrada por su aceptación generalizada y su perdurabilidad en el tiempo. No existe, en la historia de la literatura argentina, un caso 
igual o parecido : Juan María Gutiérrez y Esteban Echeverría resultan, así, cofundadores de la literatura nacional.

Y una segunda : esta comprobación no invalida las numerosas lecturas críticas que se han hecho, a lo largo de casi dos siglos, a propósito de la obra de Echeverría sino que obliga, nos obliga- a revisitar ese origen poniendo entre paréntesis las certidumbres de las que solíamos partir.

\section{NOTAS}

1. El primero se publica sin título ni nombre de autor en la Gaceta Mercantil, el 8 de julio de 1830. (Recién se sabrá a quién pertenece cuando Echeverría lo incluya bajo el título "El regreso" en el volumen de Los Consuelos en 1834. Un año después, 1831, publica "Profecía del Plata antes de la Revolución de Mayo" en el Diario de la Tarde, Comercial, Político y Literario y, meses después, "A la Independencia Argentina" en el mismo periódico. En 1831 hace imprimir un folleto en verso titulado Elvira o La novia del Plata. En los anuncios comerciales de la prensa se aclara que se trata de un "Poemita original Argentino".

2. Félix Weinberg, Esteban Echeverría..., op.cit.

3. La sátira, en su furor patriota, incluye hasta una temprana reivindicación de la soberanía argentina sobre las Islas Malvinas, recientemente ocupadas por Inglaterra.

4. Gutiérrez, Obras Completas, op. cit..

5. Ernesto Morales, Epistolario de Juan María Gutiérrez, Buenos Aires, 1942 (El subrayado me pertenece).

6. Ver Félix Weinberg, op. cit.

7. Abel Chaneton, Retorno de Echeverría, Buenos Aires, Editorial Ayacucho, 1944.

8. Ver la historia de Lucía Miranda en La Argentina de Ruy Díaz de Guzmán y Cristina Iglesia, "La mujer cautiva : mito, cuerpo, frontera" en Georges Duby y Michelle Perrot, Historia de las mujeres, volumen III, Madrid, Taurus, 1992. Echeverría habría conocido el episodio de la crónica de Ruy Díaz porque, según Gutiérrez, planeaba dos obras teatrales : una de ellas tendría, precisamente, el nombre de uno de los caciques de esta historia, Mangora.

9. Diario de la Tarde, № 1879, Buenos Aires, 1837. Citado por Weinberg, op. cit.

10. Ibid.

11. Ibid.

12. Rojas, op. cit..

13. La conjetura es una herramienta clave en el proceso de nuestra fundación literaria.

14. Rojas, op. cit..

15. Sarlo, op.cit..

16. Ver Jorge Monteleone, "La pasión y el desierto" y Fermín Rodríguez, "Un desierto de ideas" en Alejandra Laera y Martín Kohan (comps.), op.cit., para nuevas y sugerentes lecturas del poema. 17. Weinberg reconoce que no existen registros periodísticos de estas lecturas para el mes de setiembre de 1837, fecha que les atribuye Gutiérrez, como sí los hubo para las reuniones anteriores. Sugiere que, probablemente, esas lecturas se habrían realizado en los meses siguientes (octubre o noviembre) cuando debido, quizás, al incremento del control por parte del gobierno rosista, los diarios ya habrían decidido no publicar las actividades del Salón. Abel 
Chanetón llega a afirmar que estas lecturas habrían sido escritas en fecha posterior, cuando el poeta se encontraba ya en el exilio. Ver ambos autores en libros ya citados.

18. Esta frase forma parte de la extensa nota al pie que Gutiérrez coloca a la primera vez que pone en circulación "El matadero" y a la que denomina Advertencia en la Revista del Rio de la Plata en 1871 y que vuelve a reiterar sin cambios cuando integra este texto al quinto y último volumen de las Obras Completas de Echeverría en 1874.

19. Ninguna de las apuestas críticas del siglo XX sobre "El Matadero" escapa a las sugerencias de la "Advertencia". Patricio Fontana y Claudia Román analizan estas variadas interpretaciones de "El matadero" a las que consideran "ficciones críticas" en un ensayo escrito con rigor y osadía que permite, gracias a la inclusión de la posibilidad de una co-autoría, un cambio drástico en la consideración de la historia de la crítica de este texto. Ver "De la experiencia de vida a la autoría en cuestión. Notas sobre las ficciones críticas en torno a "El Matadero", en Cuadernos del SurLetras, Departamento de Humanidades, Universidad Nacional del Sur, 2012 ; ver también Emilio Carilla,"Juan María Gutiérrez y El matadero", Thesaurus, XLVIII, 1, 1993.

20. Ver Alejandra Laera, "Sin olor a pueblo". La polémica sobre el naturalismo en la literatura argentina" en Revista Iberoamericana, vol. LXVI, N 190, Enero-Marzo 2000.

21. Ricardo Rojas, op. cit.

22. Ver Soledad Quereillac, "Echeverría bajo la lupa del siglo XX”, en Alejandra Laera y Martín Kohan, op. cit., donde propone un vasto y complejo panorama de las lecturas de Echeverría en el siglo XX.

23. . Ver Noé Jitrik, El fuego de la especie, Buenos Aires, Siglo XXI, 1970. El ensayo es también rico en sugerencias sobre la relación de Echeverría con el lenguaje popular y el lenguaje elevado.

24. . David Viñas, "El escritor liberal romántico" en Literatura argentina y realidad política. De Sarmiento a Cortázar, Buenos Aires, Ediciones Siglo XX,1971.

25. Ibid.

26. Ricardo Piglia,"Echeverría y el lugar de la ficción", en La Argentina en pedazos, Ediciones de la Urraca, Buenos Aires, 1993 ; Martín Kohan, "Las fronteras de la muerte" en Alejandra Laera y Martín Kohan, op. cit.

27. 27. He propuesto esta hipótesis en "Martires o libres : un dilema estético. Las víctimas de la cultura en El Matadero de Echeverría y sus reescrituras" en Letras y divisas, ensayos sobre literatura y rosismo, Buenos Aires, Eudeba, 1998.

28. Patricio Fontana "El crítico como hacedor de autores. Juan María Gutiérrez y las Obras completas de Esteban Echeverría", en Lidia Amor y Florencia Calvo (comps.), Historiografías literarias decimonónicas. La modernidad y sus cánones, Eudeba, Buenos Aires, 2011.

\section{RESÚMENES}

El artículo analiza y subraya la importancia de las operaciones críticas con respecto a la figura y a la obra de Esteban Echeverría desde el siglo XIX al XX. Estas intervenciones fundan un origen para la literatura nacional en el siglo XIX en dos etapas (1837-1870) y refundan ese origen con otros textos del autor en el siglo XX. El trabajo también se ocupa de los usos a que se somete la obra de Echeverría según las urgencias y necesidades de las coyunturas políticas de nuestra historia. 
Cet article analyse et souligne l'importance des opérations critiques dont la figure et œuvre d'Esteban Echeverría ont fait l'objet au XIXe et XXe siècles. Ces lectures établissent un moment de fondation pour la littérature nationale au XIXe siècle en deux étapes (1837-1870), puis, au XXe siècle, d'autres textes de l'auteur vont être lus et l'instance fondatrice de la littérature argentine sera redéfinie. Ce travail s'occupe également des usages auxquels l'œuvre d'Echeverría a été soumise selon les urgences et les nécessités des conjonctures politiques de notre histoire.

This article analyzes and highlights the importance of critical operations on the figure and the works of Esteban Echeverría in the 19th and 20th centuries. In the 19th century these approaches define two stages in the foundation of a national literature (1837-1870), but in the 20th century other texts of Echeverría are read and this origine is redefined. This article also deals with the uses of Echeverría's works in the 20th century, according to the peculiarities and the needs of political situations throughout our history.

ÍNDICE

Mots-clés: littérature nationale ; histoire littéraire ; fondations de la critique

Keywords: national literature ; literary history ; foundations of criticism

Palabras claves: literatura nacional ; historia literaria ; fundaciones de la crítica 